\title{
No hay dos sin tres
}

\author{
El Tercero | Rodrigo Guerrero | 2014 \\ Lucía Bringas" \\ Escuela de la Orientación Lacaniana
}

Recibido: 23 de mayo 2016; aprobado: 09 de junio 2016

\begin{abstract}
Resumen
Mediante un recorrido sobre la función del tercero en conocidos casos clínicos y literarios del psicoanálisis, se realiza un análisis de la película "El Tercero" de Rodrigo Guerrero.
\end{abstract}

Palabras clave: amor $\mid$ sexo $\mid$ el tercero

There are no two without three

\begin{abstract}
Through a tour of the role of the third in known clinical psychoanalysis and literary cases, an analysis of the Rodrigo Guerrero's film "The Third" is performed.
\end{abstract}

Keywords: Love | Sex | The third

El encuentro con la sexualidad es traumático para todo el mundo. A diferencia de los animales que son guiados por el instinto hacia su meta sexual, en la especie humana no hay programación natural acerca de cómo conducirse con el otro sexo, no está escrito. La complementariedad perfecta, lo que llamamos la media naranja que unidas forman una, no existe. La existencia del lenguaje incide en los cuerpos, y sus modos de satisfacción; desde que hay lenguaje no hay más armonía y el paraíso está perdido. No hay brújula que oriente acerca de cómo ser hombre, cómo ser mujer, ni cómo hacer pareja, no viene determinado en los genes, ni lo define la anatomía, no hay manual de instrucciones ni tutorial que nos oriente. Podríamos decir que cada vez menos desde la caída de lo que en otras épocas orientaban a los sujetos, nos referimos a las tradiciones, los grandes ideales y de lo que llamamos "moral civilizada" en el sentido de Freud. Los estereotipos culturales sobre lo masculino y lo femenino están en plena mutación. Cada uno deberá arreglárselas con este agujero que es de estructura, y lo que uno construya allí está abierto al malentendido, al azar, a la contingencia y a la invención. Tenemos un axioma lacaniano para decir esto: "la relación sexual no existe".

Freud inventó el psicoanálisis en plena época victoriana, en un régimen que bajo las banderas del ideal y la moral, propició la represión, la abstención sexual, la renuncia, la castidad, la culpa y la vergüenza. El psicoanálisis surge como una respuesta a ese malestar de la civilización. La Reina Victoria fue la condición de posibilidad del psicoanálisis, discurso que surge como subversivo, como el reverso del discurso dominante, levantando represiones, agujereando los semblantes, abriendo la vía para la liberación del goce.

De la reina Victoria a hoy, los tiempos sin duda han cambiado, - quizás el psicoanálisis algo tiene que ver con ello-, y esta película nos lo muestra: el lugar que tiene la sexualidad, sin duda, ha cambiado. Lo que antes era prohibido hoy está permitido, es posible, ingresa en lo cotidiano sin que implique ninguna transgresión, se muestra en tiempo real sin pudores, culpa ni vergüenza. Cuestión que pone al psicoanálisis a preguntarse cómo estar a la altura de la subjetividad de su época, cómo dar una respuesta al padecimiento subjetivo de hoy que no es el mismo que el de la época de Freud.

Jacques-Alain Miller, en su presentación al Congreso de la AMP del 2016, se pregunta acerca de los cambios en la sexualidad en su régimen actual, y nos propone definir este cambio de época (Miller, 2014). Hoy la sexualidad es filmada y exhibida, hay un pasaje de lo privado a lo público propiciado por los avances tecnológicos, de lo que

luciabringas@hotmail.com 
llamamos la era virtual. Se trata de la difusión masiva del porno, lo que antes implicaba una prohibición, censura o transgresión, ingresa a la vida cotidiana y es accesible para todos a un simple clic del mouseen la comodidad del propio hogar. Los tiempos cambian y el psicoanálisis cambia con la época; es preciso, si no quiere correr el destino de ser un síntoma olvidado. Allí, Miller convocó a dar cuenta de una clínica de la pornografía del siglo XXI. ¿Cómo incide esta exhibición sexual al alcance de todos en las subjetividades, en los lazos, en los jóvenes que se inician?, ¿podrá esta exposición, a escala global, del acto sexual en todas sus variaciones enseñar a los sujetos a cómo manejarse con el partenaire?, ¿dan la clave?, ¿ son la solución al impasse sexual? Nada de eso pareciera posible.

Ya Freud se encontró con esta desarmonía radical, esa fractura, esa falta de programación natural entre los seres sexuados, allí estamos siempre en el reino del desencuentro, el malentendido y los embrollos. La variedad de casos clínicos que Freud nos dejó, dan cuenta de que ni la sexualidad ni el deseo se dejan domesticar por las convenciones, las etiquetas ni las normas.

Por ejemplo el caso clínico conocido como caso Dora (Freud, 1905 [1967]), es paradigmático. Dora, una jovencita de 18 años, inteligente, de buena familia, es cortejada por el Sr. K., un buen candidato, que a pesar de estar casado con la señora K coquetea con Dora. Freud se encuentra con que Dora no tiene la menor intención de romper este triángulo, y empieza a advertir el interés que Dora tiene por la Sra. K. Este interés radica en que para Dora, la Sra. K. tiene la clave de lo que es ser una mujer (Lacan, 1957-1958 [2010]). Para eso es que Dora necesita sostener este triángulo amoroso. El Sr K. es quien posibilita a Dora acceder a la Sra. K.

Cuando el Sr. K, creyéndose el destinatario del amor de Dora le dice: "mi mujer no me interesa", "no es nada para mí”, el triángulo fantasmático se rompe y Dora en vez de ponerse contenta, le da una cachetada que pasó a la historia del psicoanálisis.

También Freud llega a confundir este interés de Dora por el Sr. K con amor, y es tiempo después que advierte su error, agregando en una nota al pie de página del historial escrito, que sin duda hubo algún error por su parte, y que hubiera debido comprender la dimensión del apego homosexual por la Sra. K., verdadero interés de Dora.

Como histérica, ella necesita a la Otra mujer para acceder a un hombre. Ella no ama al Sr. K pero le es indispensable, y le es mucho más indispensable que él desee a la Sra. K.
Freud, un hombre de avanzada para la época, sin embargo en algunos momentos pisa el palito, dirige la cura pensando en cierta complementariedad posible entre el hombre y la mujer, en que el muchacho es a la muchacha lo que el hilo a la aguja... y envía a las histéricas a buscar al hombre correspondiente. En otro caso, sugiere a Elizabeth Von R. que se case con su cuñado cuando muere la hermana, sin darse cuenta de que ella estaba enamorada de ese hombre justamente porque era el marido de su hermana y cuando ya no lo es, Elizabeth deja de interesarse en él. El cuñado no valía como hombre sino que valía para ella por su relación a la Otra, aquella que para Isabel representaba el enigma de lo femenino y tenía la respuesta acerca de que es ser una mujer. Es lo que se ve claramente en Dora y que se escuchamos aún hasta nuestros días.

Se trata de que el estatuto mismo del deseo pone a jugar al tercero. Lacan dirá que el deseo es el deseo del Otro, esto implica que basta que otro desee algo para que eso empiece a interesar.

En el caso del obsesivo, encontramos con asiduidad que el tercero puede ser un recurso siempre útil para evitar o tornar imposible el encuentro amoroso. Distintos triángulos posibilitan a los sujetos mantenerse en la eterna duda y así impedir la realización del deseo. El llamado Hombre de las Ratas, caso freudiano paradigmático, es un fiel ejemplo de como el sujeto divide el objeto de amor idealizado en la dama de sus pensamientos y el deseo degradado en la mujer cualquiera, devaluada. Esta división del amor y el deseo, entre la madre y la puta posibilitan la duda al infinito.

Sigamos con los triángulos. Lacan rinde un homenaje a Marguerite Duras y su novela El arrebato de Lol.V. Stein (Duras, 1987), y allí subraya la función del tercero. Lol, la joven protagonista logra una solución que pasa por lo que Lacan llama el ser de a tres, luego de una escena en un baile en que su novio le es arrebatado por otra mujer, una mujer misteriosa,femme fatal. Luego de un período que Marguerite describe como "sin palabras", Lol encuentra una solución en el triángulo conformado por su amiga Tatiana, y su amante. Lol necesita del sostén especular del cuerpo de su amiga para sentir que ella misma tiene un cuerpo. El cuerpo de la otra le permite recuperar algo de su cuerpo, caído luego del episodio del baile. La mirada es la protagonista de la escena.

Y así podríamos seguir hasta el triángulo más famoso de todos: el Edipo, triángulo fundamental y fundante: el lugar y el modo en que cada sujeto habite este triángulo sentará El tercero es un nombre que en el psicoanálisis 
nos resulta muy familiar, hablamos de la función del tercero como el lugar del padre en el Edipo, función simbólica que viene a cortar o a intervenir en la relación dual madre-hijo. También está el nudo borromeo, el nudo de 3, real, simbólico e imaginario; los tres tiempos lógicos; una conferencia muy importante que Lacan dictó en Roma con el nombre de La Tercera (Lacan, 1974 [2010]), el trípode de la formación del analista: análisis, episteme, control, y podríamos seguir.

Lo que los casos recorridos dan cuenta es que el tercero es un fantasma recurrente desde que el mundo es mundo. Frente al agujero que implica la falta de programa que indique la relación perfecta con el partenaire, lo que llamamos a partir de Freud el fantasma o la fantasía fundamental fija un modo de goce, en una escena imaginaria, fantaseada y repetida. Entonces el tercero es un fantasma recurrente, habrá que ver que función cumple cada vez, en cada caso, en cada fantasía, que posibilita que solucione, que sutura, que obstaculiza. Así como decimos en las novelas detectivescas, cherchez la femme, podríamos decir frente a cada pareja amorosa, ¡busquen al tercero!

Lo interesante que la película introduce es que aquí el fantasma del tercero no queda operando a nivel de la fantasía y del deseo siempre insatisfecho, reprimido sino que se realiza, y se muestra con naturalidad, sin culpas, transgresiones ni velos en un día como cualquier otro y en tiempo real.

Quizás la película nos expone algo de este cambio de época, de la de Freud a la nuestra, donde antes la satisfacción pasaba más por la renuncia y la privación, hoy la época incita a no quedarse con las ganas, a cumplir las fantasías, a atravesar las inhibiciones. Hay un empuje a la satisfacción total, en donde lo que antes se fantaseaba, hoy se realiza y se muestra, pasando así de la esfera privada a la pública. No se trata aquí de transgresión sino que el goce está permitido e ingresa en lo cotidiano.

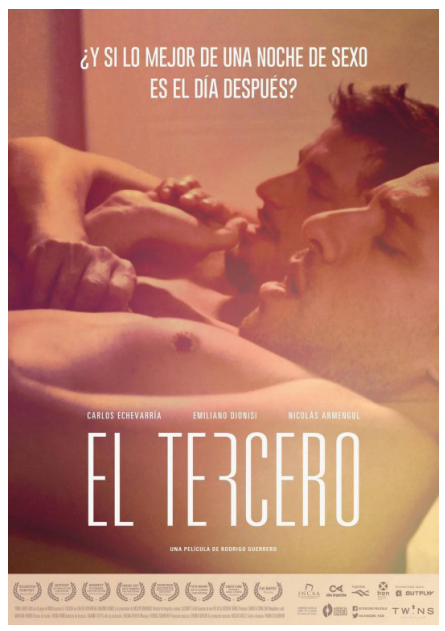

Considero a destacar como la película muestra el protagonismo que tiene la mirada en sus personajes. Hay una satisfacción o gustito de mirar, a la que Lacan le dio el estatuto de pulsión, la llamada pulsión escópica. Glotonería de la mirada que se muestra en distintas escenas, desde el encuentro en la webcam, en la ducha, mirar desde el balcón como gozan los vecinos, un mundo transparente, panóptico, sin velos, en donde todo se ve, rasgo de esta época en donde el ojo está en el lugar dominante.

En esta línea propongo pensar la escena final en donde aparece esa voz en off de la profesora de arquitectura hablando de cómo hacer un plano o una maqueta en perspectiva, y el punto principal, el punto de fuga, ese punto a donde se dirige o fija la mirada, y hacia donde convergen los distintos planos.

La escena de la cama trasmite una unión de 3 cuerpos que pareciera querer encastrar como piezas de un rompecabezas, imagen de potencia, y de armonía, goce pleno, nada falta, nada sobra. Uno de los personajes lo enuncia en el balcón: hombres, mujeres y animales, todo el mundo copulando a la vez, acabando todos juntos, y que el mundo explote, imagen de un goce universal, total, ¿después de eso qué más? solo queda la muerte.

Nada pareciera empañar la satisfacción, no aparecen los afectos típicos como los celos, o la rivalidad, ni el clásico tercero excluido. La película nos muestra una escena de tres que hacen uno, especie de fusión sin resto ni pérdida.

Es como si el tercero anudara algo de esta pareja, suturara una hiancia que se pone en juego en la conversación durante la cena, allí cuando ingresa la palabra aparecen las discordias típicas de la comedia de los sexos, “...que tu mamá, que la mía, que por qué cocinaste remolacha que no me gusta... mirá como sos...”, en fin, los desencuentros, la seducción, los miedos, el paso del tiempo, la calvicie, incluso la muerte se hacen presentes. "Después de 8 años algo hay que inventar" y el tercero estuvo presente desde el inicio de la relación, había dos que estaban atrás.

Es muy interesante esa "cita de a tres", esa conversación en tiempo real de la cena, en apariencia banal. Algunas perlitas son: estos sujetos hipermodernos, que reivindican su derecho a gozar y a sostener su orientación sexual por fuera de las tradiciones, cuando empiezan a hablar de ellos mismos, terminan hablando de la parentela, del papá y la mamá, sobre todo de la mamá, "del Edipo no resuelto" ¿Esto demuestra la vigencia del Edipo más allá de los tiempos? Quizás estos persona- 
jes representan algo así como una generación bisagra, la nuestra, el momento de un cambio de paradigma, el fin o la caída de la familia tradicional, del papá y la mamá y el inicio de nuevas formas de enlazarse o de "hacer familia" por fuera de las convenciones.

Y finalmente, sin duda, "el" detalle de la película: el signo del amor entre ellos no es ni la potencia, ni la belleza, ni los cuerpos musculosos, ningún semblante fálico. Aquello que los encontró fue "la cara de monito" único signo de vergüenza, de pudor, de timidez.

Constatamos así, una vez más, que en la era del imperio de la imagen y de la exhibición de lo que hay, de lo que se tiene, de ese empuje a mostrar todo lo propio de la época, el amor aún, se dirige a lo que falta en el otro. Es un dato pintoresco en estos estos sujetos que parecieran no intimidarse por nada, que se dicen de todo, y hacen de todo, sin tapujos sexuales, sin inhibiciones ni pudores.
Sin embargo, en algún lado, aparece la vergüenza y allí se produce el encuentro amoroso. Allí Federico, personaje que representa al tercero en la pareja dice: "yo también hubiese caído rendido", signo de amor en donde se encuentran los tres.

Y en este punto les propongo pensar que la película deja de ser pornografía, tal como la clasifican en los sitios web, para transformarse en una historia de amor.

En fin, la "cara de monito", ese abrazo que intenta anudar a los tres, las risas y las miradas, anuncian lo que el día después, se enuncia: “¿vas a volver?, ¿ me van a invitar?”.

Señal de que lo contingente se torna necesario y a partir de aquí podemos decir que ya no se trata de "sólo sexo".

No sabemos qué sucedió o cómo sigue; nadie lo sabe, porque hoy, como ayer, como siempre, pero hoy más que nunca, no está escrito.

\section{Referencias}

Duras, M. (1987). El arrebato de Lol.V. Stein. Barcelona: Tusquets.

Freud, S. (1905 [1967]) “Análisis fragmentario de una Histeria” en Obras Completas, Tomo II, López Ballesteros. Madrid: Editorial Biblioteca Nueva.

Freud, S. (1967) “La Histeria” en Obras Completas, Tomo. I, López Ballesteros. Madrid: Editorial Biblioteca Nueva.

Freud, S. (1967). “Análisis de un caso de neurosis obsesiva” en Obras Completas, Tomo II, López Ballesteros. Madrid: Editorial Biblioteca Nueva.

Lacan, J. (1957-1958 [2010]) “Las formaciones del inconsciente” en El seminario de Jacques Lacan. Libro 5. Buenos Aires: Paidós.

Lacan, J. (2010). “Homenaje a Marguerite Duras, del Rapto de Lol. V. Stein” enIntervenciones y textos 2. Buenos Aires: Manantial.

Lacan, J, (1974 [2010]). “La Tercera” en Intervenciones y textos 2. Buenos Aires: Manantial.

Miller, J-A. (8 de octubre de 2014). El inconsciente y el cuerpo bablante. Recuperado el 20 de julio de 2016, de Asociación Mundial de Psicoanálisis:http://www.wapol.org/es/articulos/Template.

Miller, J.-A. (2004). Conferencia de Jacques-Alain Miller en Comandatuba. Recuperado el 20 de Julio de 2016, de VIII Congreso de la Asociación Mundial de Psicoanálisis AMP: http://www.congresoamp. com/es/template.php?file=Textos/Conferencia-de-Jacques-Alain-Miller-en-Comandatuba.html 